\section{The Biological Heart Valve in Aortic Position and its Effect on the Brain}

\author{
Wilhelm P. Mistiaen* \\ Faculty of Medicine and Health Sciences, University of Antwerp, Antwerp, \\ Belgium \\ Department of Healthcare, Artesis-Plantijn University College of Antwerp, \\ Antwerp, Belgium
}

\begin{abstract}
Thromboembolic events are a major complication of valve replacement. Most of these occur in the brain, with devastating consequences. Biological heart valve prostheses have been designed to reduce these complications as much as possible. This has the advantage that they require less antithrombotic agents compared to mechanical valves. However, thromboembolic events still do occur. The main question is: are such devices thrombogenic on long-term? For this reason, only long-term results have been included. A literature review reveals that there are several sources of emboli: the diseased native valve itself as well as other cardiovascular conditions such as atrial fibrillation or poor left ventricular function. Annual rate of thromboembolism of different series have been compared as well as the effect of several antithrombotic regimens during the first three postoperative months, since this is the most hazardous period. The results of trans-catheter aortic valve implantation have also been added since this is a way to treat patients who cannot stand the trauma of valve surgery. High age and risk scores make comparison with valve surgery difficult however. In either case, the rate of thromboembolism is rather low. Anticoagulation is probably needed within the first three months. If additional risk factors are present, life-long anticoagulation becomes necessary. However, there are some serious limitations in this review. The most important are the lack of standardization of recording embolic events and the value of possible surrogate parameters such as brain lesions on magnetic resonance imaging and cognitive decline. Large scale randomized controlled trials to identify the best antithrombotic protocol are difficult to design: because of confounding patient-related risk factors, large patient number needed to detect significant differences, and large variations in possible combinations of agents. However, every effort should be made to register every event in an adequate and standardized way.
\end{abstract}

*Corresponding author: Wilhelm $\mathrm{P}$ Mistiaen, MD, ScD, PhD, Artesis-Plantijn University College, J De, Boekstraat 10, 2710 Antwerp, Belgium, Tel: 323-641-8241; Fax: 323-641-8271; E-mail: wilhelm.mistiaen@uantwerpen.be; wilhelm.mistiaen@ap.be

Citation: Mistiaen WP (2014) The Biological Heart Valve in Aortic Position and its Effect on the Brain. J Cardiol Stud Res 1: 002.

Received: May 15, 2014; Accepted: June 24, 2014; Published: July 08, 2014

Copyright: (c) 2014 Mistiaen WP. This is an open-access article distributed under the terms of the Creative Commons Attribution License, which permits unrestricted use, distribution, and reproduction in any medium, provided the original author and source are credited.
Keywords: Stroke; Thromboembolism; Aortic valve replacement; Biologic heart valve

\section{Abbreviation}

TE: Thromboembolism

AVR: Aortic Valve Replacement

BHV: Biological Heart Valves

MHV: Mechanicalheart Valves

VKA:Vitamin K Antagonists

AF: Atrial Fibrillation

CVA: Cerebrovascular Accident

TAVI: Trans-catheter Valve Implantation

MRI:Magnetic Resonance Imaging

TIA: Transient Ischemic Attack

VARC: Valve Academic Research Consortium

AS: Aortic Valve Stenosis

DAPT: Dual Anti-Platelet Therapy

AF: Atrial Fibrillation

RCT: Randomized Controlled Trial

CABG: Coronary Artery Bypass Grafting

ASA: Acetylsalicylic Acid

INR: International Normalized Ratio

\section{Introduction}

Thromboembolism (TE) with neurologic deficit/stroke is one of the most potentially devastating long-term complications after Aortic Valve Replacement (AVR). By valve replacement, one condition (valve disease) is substituted by another, the valve prosthesis. This inherently is associated with life-long complications such as TE. This can vary according the type of valve. There are two major types of valves: Biological and Mechanical Heart Valves (BHV, MHV). The early mechanical valves were of "ball and cage type" with high rates of TE events and one-quarter fatality rate. Anticoagulant therapy with Vitamin K Antagonists (VKA) reduced but did not eliminate the problem [1]. Anticoagulant regimen requires close follow-up because of the risk for bleeding complications. Preoperative events, prosthesis design and Atrial Fibrillation (AF) were identified as additional risk factors for TE. In most patients, signs and symptoms after emboli resolved [2]. BHV have been developed to reduce the risk for postoperative TE, in order to avoid the routine administration of VKA [3]. Already 30 years ago, it has been demonstrated that long-term TE does not differ in a considerably degree between BHV (whose patients are mostly not anticoagulated) and a tilting-disc MHV [4]. This has been confirmed in a more recent nationwide retrospective comparison of MHV and BHV. The crude cumulative incidence of TE events, at 1, 5 and 10 years was very comparable [5]. Furthermore, one of the very few prospective studies, including only patients between 55 and 70 years of age showed an annual rate of TE in patients with BHV of $0.24 \%$; for MHV, this was $0.54 \%$. The rate of other valve related events were comparable. This makes the risk for structural valve degeneration decisive in the choice for a valve in this difficult age group [6]. Some other studies showed results in favor of $\mathrm{BHV}$ with a significant risk ratio of 0.87 , indicating a reduction of $13 \%$ 
[7], while others found a significantly lower TE event rate for MHV [8]. The price of avoiding anticoagulation, with its increased risk for bleeding, is structural valve degeneration and reoperation [9].

The focus of this manuscript is directed on the tendency to develop long-term TE events after implantation, either surgically or through catheter-based techniques. Our own results with Carpentier-Edwards pericardial valve show a linearized rate of $1.8 \%$ PTY. The predictors factors for the observed long-term TE included prior Cerebrovascular Accident (CVA) and hospital TE, indicating that TE might be triggered by the prosthetic valve, at least in some patients [10]. This indicates that not all TE events are necessarily device related. The aim of the paper is to review patient related and device related risk factors for $\mathrm{TE}$ as well as proper definition and documentation of TE events. Inclusion of series studying long-term $\mathrm{TE}$ events in patients undergoing aortic valve repair and of Trans-catheter Valve Implantation (TAVI) shows interesting comparative results. Procedural TE events are therefore not included. The clinical significance of silent events and their documentation on Magnetic Resonance Imaging (MRI) also deserves some consideration. Most TE events are located in the brain; however, not all manuscripts make a distinction between TE events and ischemic stroke or Transient Ischemic Attack (TIA). The termis maintained throughout the paper because all emboli originating from the heart valve have a potential risk of causing stroke. The definitions of stroke and TIA have been updated in the Valve Academic Research Consortium or VARC-2 document and concern the neurologic events after TAVI [11].

\section{Methods}

A search through ISI web of knowledge was performed with the search terms: "aortic valve replacement AND thromboembolism", from 2009-2014. This resulted in 72 hits, of which 23 were excluded on abstract or title (pediatric series, Ross procedure, animal or in vitro experiments, pregnancy issues, other than aortic valves). The additional search term "aortic valve replacement and stroke" resulted in 515 hits, mostly concerning TAVI. Exclusion criteria were: series concerning only early or procedural stroke, focus on imaging modalities, case studies, other valve positions, other outcomes than TE events, issues of access of TAVI. After identification of double papers, three papers could be added. Eight papers we included for historical reasons.

\section{Results}

A stenotic aortic valve (AS) is considered as having anintermediate-risk level for stroke [12]. Concomitant aortic annular calcification also plays a role. This relation with TE events is present, even after correction for age, gender, body mass index, physical activity, creatinine, systolic blood pressure, total and high-density lipoprotein cholesterol, smoking, diabetes, coronary artery disease and heart failure. This relationis considered as causative. Friable ulcerated calcium deposits and thrombi are observed in $1 / 3$ of autopsy series of patients with aortic valve calcific disease $[13,14]$. There are some competing causes for cerebral emboli: small vessel disease, Atrial Fibrillation (AF), low cardiac output, atherosclerotic disease of supra-aortic vessels and complex (large, ulcerated and mobile) plaques of the aortic arch as well as hypoperfusion of the brain [14-16]. Such plaques are more frequent and complex if aortic valve calcification is present [15]. However, there is an interrelation between these factors: in patients with mild-to-moderateAS, chronic AF can increase non-hemorrhagic stroke almost 5 times, while hypertension and atherosclerotic disease are considered as confounders [17]. Diagnostic catheter procedures in patients with AS can also cause neurological deficit. Such post-procedural neurologic deficit is more common with plaques in the aortic arch [15]. Stroke rate after medical treatment of ASis also $2 \%$ after 1 year [18].

Table 1 shows the results of 6 patient series in which a biological valve was implanted in aortic position. The mean age of the patients is above 70 in four of these series. The results are given as a linearized rate and vary between 0.4 and $2.2 \%$ per patient-year. This is in line with our own results [10]. Interestingly, one review including 3000 patients who underwent valve repair show low TE event rates, which seem superior to AVR [19]. This is confirmed in another series where freedom from combined thromboembolism and bleeding is $96 \%+/$ $2 \%$ at 8 years [20]. Few studies however provide the more adequate rates of freedom of TE after a given interval. Remarkably, the freedom of TE at 10 years was 97.7 years in one series [21], while in another series, at 15 years, this freedom of TE events was $89.4 \%$ [22]. The mean age in the latter series was 42 years, making early structural valve degeneration a likely mechanism for this increase in TE events.

\begin{tabular}{|c|c|c|c|c|}
\hline Reference & Design/type & Mean age & comorbidity & TE (\%pt-y) \\
\hline Beholz [59] & Stentless & 74 & - & 0.7 \\
\hline Jamieson [60] & Silzone & 59 & - & 0.4 \\
\hline Chan [41] & Stentless & 56 & - & $0 / 11$ at $7.5 \mathrm{y}$ \\
\hline Merie [27] & Nationwide & 77 & AF excluded & 1.3 \\
\hline Brennan [7] & STS/Medicare & 73 & - & 2.2 \\
\hline Saczkowsky[19] & Repair & - & - & $0.5(0.00-0.95)$ \\
\hline Boodhwani [20] & Repair & 44 & - & $4 \%$ at 8 y \\
\hline
\end{tabular}

Table 1: TE after (aortic) valve replacement with BHV.

AF: Atrial Fibrillation; BHV: Biological Heart Valve; Pt-Y: Patient-Year; TE: Thromboembolism; Y: Year.

Table 2 shows the effect of the postoperative regimen during the first three months after AVR. Two older series could serve as baseline. The first series recommended aspirin as routine use after implantation of BHV in aortic position [23]. The second one suggested VKA should be given for at least 3 months, and life-long if risk factors are present [24]. More recent series fail to show major differences between different anticoagulation regimens. This can be partly due to differences in study design. In one series from 2010, patients under postoperative VKA were older, had more symptoms and more comorbid conditions. VKA were most effective in patients with risk factors such as female gender or in New York Functional Class III/IV [25]. One series shows that the incidence of TE, three months after AVR is $0.9 \%$, which is low, but in presence of risk factors, this becomes higher (1.3\%). Three-quarter of these events is neurologic. The combination of VKA and aspirin lowers the occurrence of TE significantly, but at the expense of increased bleeding rate, hence this regimen should be offered only in patients with low risk for bleeding [26]. A nationwide retrospective study reveals that discontinuation of VKA increases the risk for stroke and other TE events much more after 1-3 months (2.5 to3 times) compared to discontinuation at 3-6 months ( 1.0 to 2.5 times) or on a later time( 0.8 to 1.2 times). VKA are clearly beneficial in the first three postoperative months [27]. TE events patients undergoing valve replacement for rheumatic heart disease are only observed within the first month, but not in the second and third month. Moreover, these patients are much younger [28]. The type of BHV does not seem to play a role: comparison of 
Carpentier-Edwards pericardial and Mosaic reveals no differences after 6 year follow-up [29]. Remarkably, compared to VKA, aspirin resulted in a lower TE event rate after AVR with concomitant CABG [30].

\begin{tabular}{|l|l|l|l|c|}
\hline Reference & Design & Exclusion & \%TE & $\mathbf{p}$ \\
\hline Blair [23] & - & - & $\begin{array}{l}\text { VKA: } 2.9+/-1.6 \% \\
\text { ASA: } 0.8+/-0.2 \% \\
\text { No: } 1.5+/-0.6 \%\end{array}$ & NS \\
\hline Heras [24] & - & none & $\begin{array}{l}\text { With VKA: }+/-4 \% \\
\text { Without VKA: +/-3\% }\end{array}$ & NS \\
\hline ElBardissi [25] & Only SR & $\begin{array}{l}\text { Preoperative VKA } \\
\text { Concproced } \\
\text { Postop chron AF }\end{array}$ & $\begin{array}{l}\text { With VKA: +/-5\% } \\
\text { Without VKA: +/-5\% }\end{array}$ & 0.67 \\
\hline Brennan [26] & $\begin{array}{l}\text { Database } \\
\text { search }\end{array}$ & $\begin{array}{l}\text { Preoperative VKA } \\
\text { VKA contraindi- } \\
\text { cated }\end{array}$ & $\begin{array}{l}\text { ASA: }+/-1 \% \\
\text { VKA: }+/-1 \% \\
\text { ASA+VKA: }+/-0.5 \%\end{array}$ & NS \\
\hline Merie [27] & Nationwide & $\begin{array}{l}\text { Preoperative VKA } \\
\text { AF }\end{array}$ & $\begin{array}{l}\text { With VKA +/-4\% } \\
\text { Without VKA }+/-13 \%\end{array}$ & $\mathrm{p}<0.05$ \\
\hline Colli [30] & - & $\begin{array}{l}\text { Preoperative VKA } \\
\text { AF, PCl }\end{array}$ & $\begin{array}{l}\text { VKA: } 2.8 \% \\
\text { ASA: } 1.5 \%\end{array}$ & p=0.33 \\
\hline Duraes [28] & $\begin{array}{l}\text { Rheumatic } \\
\text { valve; first } \\
\text { month only }\end{array}$ & $\begin{array}{l}\text { Prior TE, AF, } \\
\text { coagulopathy }\end{array}$ & $\begin{array}{l}\text { With ASA: }+/-5 \% \\
\text { Without ASA: +/-1.6\% }\end{array}$ & \\
\hline
\end{tabular}

Table 2: Three-month policy anticoagulation after AVR.

AF: Atrial Fibrillation; ASA: Aspirin; AVR: Aortic Valve Replacement Conc. Proced: Concomitant Procedures; NS: Non-Significant; $\mathrm{PCl}$ : Percutaneous Coronary Intervention; TE: Thromboembolism; VKA: Vitamin K Antagonists

Is some series, long-term TE events after TAVI is low and comparable to the results after AVR. An annual rate of less than 1\% has been observed [31]. Others observed almost doubling of events after TAVI compared to AVR, but the 30-day events, which showed a peak, were included. Long-term event rate of both procedures were comparable and this was determined by patient related risk factors such as prior TIA/CVA, advanced functional disability, and not by treatment mode, nor by procedural variables [32]. A comparable stroke rate was also found at 6 months (2.3\% for TAVI, 3.3\% for AVR), but only after adjustment for other variables [33]. Although a low stroke rate after both procedures was observed, cognitive decline after AVR is worse. However, this was only temporary and not related to focal cerebral emboli [34]. A prospective analysis reveals that stroke rate at one year was $6 \%$ after AVR, $4 \%$ after TAVI and $2 \%$ after medical treatment in elderly patients. The selection for the procedure as was according existing guidelines [18]. Finally, a meta-analysis including 17 studies and over 4500 patients revealed no major differences in stroke or TIA between TAVI and AVR. At a mean follow-up of 66 weeks, the risk ratio was 0.86 . At a mean follow-up of 99 weeks, this was 0.56 in favor of AVR, but this was not significant. Usually, three to six months DAPT was recommended, followed by aspirin [35].

Non-valvular factors such as prior cardiac surgery can reduce postoperative 5-year freedom of TE events and of stroke after AVR in octogenarians to $89.2 \%$. In younger patients, this was significantly better, being 97.5\% [36]. In contrast, patients undergoing AVR with concomitant $\mathrm{CABG}$, less TE events are recorded with aspirin, compared to VKA [30]. Another patient related factor, carotid artery stenosis, does not seem to relate to stroke after AVR/CABG [10,37,38].

\section{Discussion}

From existing series, it has become evident that a diseased aortic valve is a source of emboli. The degree of stenosis, calcification and regurgitation can be responsible for embolic stroke by damaging red blood cells through release of adenosine phosphate and thromboplastin with cloth formation $[13,14,39]$ but also through turbulence and by dislodging calcified fragments [39]. These preoperative incidents serve as predictor for postoperative TE events $[10,24]$. Hence, they have clinical relevance. Such brain infarction is associated with hemodynamic relevant AS, for which AVR is needed [40]. Aortic valve repair also leads to TE events, but at a low rate. This is probably due to young age and of preservation of the native valve [20], while AVR with biological prostheses is mostly reserved forin elderly patients with AS. Possible sites of occurrence of thrombi could be the excision site of the valve, the sewing ring, suture material and the valve tissue itself [24]. Comparing two unrelated studies, [21,22], a considerable decrease of freedom from TE events can be observed between 10 and 15 years. This might be due to structural valve degeneration which occurs mostly after 10 years. In one of the series [22] the mean age of patients is only 42 . In this age group, structural valve degeneration will occur much sooner. Such degenerated valves can calcify, become stenotic or regurgitant. As in a native diseased valve, this can cause damaging of blood cells, thereby promoting TE events. This however can only be proved by a follow-up period which exceeds 15 years. A smaller effective orifice area of stented BHV could also be responsible for some tendency of TE occurrence. Implantation of stentless valves could avoid such problems. AVR with stentless valves, however, is not a part of clinical routine because of its technical challenging character and the benefit of reduction of TE events is probably too small. The only series included [41] is too small to draw conclusions.

The three-months anticoagulation protocol after AVR with $\mathrm{BHV}$ is debatable. Biological heart valves are considered as more thrombogenic within the first three months after implantation, because or incomplete re-endothelialization [42]. This takes probably three months, the time needed to be bridged by VKA. This interval seems to carry the highest risk for TE. Prophylactic ASA seems as effective as VKA, but with less bleeding complications. Low dose ASA could be recommended in absence of other risk factors for TE such as AF, previous TE event or peripheral embolism, poor left ventricular function and coronary artery disease [43]. Especially previous TE events have been identified as predictor for future events $[10,24]$. FASA could also be recommended in patients with an increased risk for bleeding [26]. Although a three-months course of VKA reduces TE events more effective in patients over 75 years, [26], it should not be given in all patients [25]. It seems that there is no advantage using VKA to reduce TE events after implantation of a BHV, unless risk factors such as preoperative events, AF, large atrial volume and poor left ventricular function are present $[24,42,44]$. In the latter patients, adding VKA to aspirin is a better choice $[24,42]$ and an extension to 6 months has been recommended [27]. However, a three-month course of VKA in patients who received a $\mathrm{BHV}$ in aortic position has received a place in the top 10 changes in anticoagulation practices [45].

Contradictorylong-term results between series could be the result of 1) their retrospective nature, 2)too few events which makes these series under powered, 3) variation in detecting TE events, 4) application of different antithrombotic regimen, especially with newer agents such as factor Xa inhibitors, 5) patient experience and compliance, 6) stability of INR, 7) metabolic variation, 8) pharmacological interaction, 9)the surgeon's discretion concerning VKA inhibitorsand 10) other patient-related factors $[26,30,43]$. It seems that large RCT are needed to make differences between the many possible regimens visible for events that have a low 
occurrence rate $[42,26]$. The number of combinations increases exponentially with each new agent [46].

TAVI has been designed for those patients who have an unacceptable high risk for mortality after AVR or who have a so-called "hostile thorax". Implantation of a device instead of replacing it might have specific consequences on the rate of long-term TE events: the calcified valve is still in its place. Since procedural TE events are probably related to catheter manipulation and dislocation of atheromatous plaques, these events are not taken into account here. Long and mid-term stroke rates could represent the thrombogenicity of the implanted devices. Major stroke 1 year after AVR was 2.4\%; for TAVI, this was $5.1 \%$ which was significantly higher. However, the difference is due to the difference in 30-day outcome [47]. In another series, stroke rates for TAVI at 6 months are comparable to those after AVR, after adjustment for other patient variables [33]. However, patients undergoing TAVI are usually much older with higher risk scores: they probably have more risk factors for long-term post-procedural TE events [33,34]. Therefore, until proven otherwise, results of surgical AVR should not be extrapolated, only be used a benchmark. According to a recent review, one-year stroke rate (major and minor) varies between 2.5 and $5.3 \%$ and is worse compared to stroke rates in surgical patients [46]. In some series, no stroke [48] or a lower-but not significant-stroke rate is reported during long-term follow-up [49]. Post TAVI stroke remains high with risk factor prior cerebrovascular events [50]. In one prospective study, AF has a limited and insignificant effect on 1-year stroke rate (3.9 versus $5.1 \%$ with $\mathrm{P}=0.47)$. This risk is correlated with the $\mathrm{CHA}^{2} \mathrm{DS}^{2}$ score [51]. DAPT is not superior compared to aspirin at 30 days and 6 months in terms of reduction of TE events, except in patients with risk factors such as AF [52].

The interaction of the device with the native valve might generate a prothrombotic state. One could wonder if TE events after TAVI are related to platelets or to thrombin [46]. As for surgically implanted $\mathrm{BHV}$, re-endothelialization of the valve stent takes probably 3 months, which corresponds with a reduction of TE events. However, it seems that Dual Antiplatelet Therapy (DAPT) does not reduce the number of TE events but it increases the rate of bleeding. More potent antiplatelet medication such as ticagrelor might become useful. Biological implanted devices can be thrombogenic. VKA could be added to aspirin ordabigatran could also be tried. Furthermore, patient-related factors such as atrial fibrillation and low LVEF also have to be considered, as it is the case for AVR. In such patients, adding VAK to aspirin seems to be beneficial [46].

The cognitive status of patients after cardiac procedure is another matter for debate. The cognitive decline after TAVI is mild, after AVR, cognitive decline is more obvious but this effect transient. The cognitive decline at 3 months is not related to focal embolic brain injury [34]. Cognitive performance is sustained in $91 \%$ of the patients, one year after TAVI and depends on patient age, not on cerebral embolism on MRI [53]. Multiple embolic foci on diffusion weighted MRI occur more often after TAVI compared to [54,55], but these foci do not seem to have an effect on the cognitive status after 3 months. Moreover, most foci seem to disappear after 3 months [56]. One should note that white matter lesions on MRI have been described after all cardiac procedures and even in up to $20 \%$ of normal elderly persons [56]. Its significance seems unclear, however, since silent cerebral ischemia, white matter lesions and lacunar infarcts on diffusion weighted MRI are associated with cognitive decline, dementia $[14,16]$ and future stroke [14].

\section{Conclusion}

Thromboembolic events do occur in 1) diseased aortic valves, 2) BHV for which in general a three month VKA course followed by life-long aspirin treatment seems necessary, 3) in patients with additional risk factors such as AF or poor left ventricular function, for which life-long VKA treatment might be needed. Momentarily, this applies for surgically replaced valves as well as for implanted valves by TAVI. Furthermore, it is possible that, once a biological valve becomes degenerated, the rate of TE events increases again. This can become relevant in surgical patients with a long life expectancy, especially if they receive a valve at the difficult age span between 55 and 70 years of age.

\section{Limitations and Future Directions}

There are serious limitations in this review: 1) the mechanism of formation of thrombi on the device is still not fully understood (platelet hypothesis versus thrombin hypothesis); on this, however, depends the optimal antithrombotic regimen; 2) a large scale RCT is lacking and this will become more difficult with the newer antithrombotic/anticoagulating agents: the number of possible combinations increases exponentially and one could wonder which combination should be tested preferentially. 3) How large should any RCT be to make it sufficiently powered? 4) It is not certain that other markers of brain injury such as lesions on MRIare valid surrogates for TE events such as stroke. 5) Although clinically important, the relation between cerebral lesions and cognitive decline after any cardiac procedure is uncertain. 6) The quality of follow-up is a major concern [57,58]. Many minor events can be missed if patients do not keep a diary in which every event is recorded and if necessary, investigated. 7) Many series show annual rates, expressed as $\%$ per patient years. However, the TE event rate is not linear. 8) Hemorrhagic transformation of cerebral infarction should be taken into account and be differentiated from a true bleeding event. 9) Differentiation of emboli from valves or from other cardiac or arterial sources is not always possible. For example, lacunary defects on imaging are not considered as emboli. 10) Not all TE events are cerebral in nature and this distinction is not always made. Some of these issues might never be cleared up. This can be the case if the difference in TE event rate is small, in RCT comparing several antithrombotic regimens. This can also be the case in exploring the clinical relevance of costlyserial brain imaging after cardiac procedures. However, providing a universal definition of neurologic events (offered by the VARC-2 document), a standardized follow-up system in which every event is recorded and a standardized representation are easier to perform.

\section{References}

1. Akbarian M, Austen WG, Yurchak PM, Scannell JG (1968) Thromboembolic complications of prosthetic cardiac valves. Circulation 37: 826-831.

2. Vidne B, Erdman S, Levy ML (1973) Thromboembolism following heart valve replacement by prosthesis: survey among 365 consecutive patients. Chest 63: 713-717.

3. Stinson EB, Griepp RB, Oyer PE, Shumway NE (1977) Long-term experience with porcine aortic valve xenografts. J Thorac Cardiovasc Surg 73: 54-63.

4. Cohn LH, Allred EN, DiSea VJ, Sawtelle K, Shemin RJ, et al. (1984) Early and late risk of aortic valve replacement. A 12 year concomitant comparison of the porcine bioprosthetic and tilting disc prosthetic aortic valves. J Thorac Cardiovasc Surg 88: 695-705. 
5. McLean RC, Briggs AH, Slack R, Zamvar V, Berg GA, et al. (2011) Perioperative and long-term outcomes following aortic valve replacement: a population cohort study of 4124 consecutive patients. Eur J Cardio-thorac Surg 40: $1508-1514$

6. Stassano P, Di Tommaso L, Monaco M, loro F, Pepino P, et al. (2009) Aortic valve replacement: A prospective randomized evaluation of mechanical versus biological valves in patients ages 55 to 70 years. J Am Coll Cardiol 54 1862-1868.

7. Brennan JM, Edwards FH, Zhao Y, Brien OS, Booth ME, et al. (2013) Longterm safety and effectiveness of mechanical versus biologic aortic valve prostheses in older patients. Results from the society of thoracic surgeons adult cardiac surgery national database. Circulation 127: 1647-1655.

8. Hellgren L, Granath F, Ekborn A, Stahle E (2011) Biological versus mechanical prosthesis in 3279 patients from the Swedish in-patients register. Scand Cardiovasc J 45: 223-228.

9. Hammermeister K, Sethi GK, Henderson WG, Grover FL, Oprian C, et al. (2000) Outcomes 15 years after valve replacement with a mechanical versus a bioprosthetic valve: final report of the veterans affairs randomized trial. $\mathrm{J}$ Am Coll Cardiol 36: 1152-1158.

10. Mistiaen W, Van Cauwelaert P, Muylaert P, Sys SU, Harrisson F, et al. (2004) Thromboembolic events after aortic valve replacement in elderly patients with a carpentier-edwards perimount pericardial bioprosthesis. J Thorac Cardiovasc Surg 127: 1166-70.

11. Kappetein AP, Head SJ, Généreux P, Piazza N, van Mieghem NM, et al (2012) Updated standardized endpoint definitions for transcatheter aortic valve implantation: the valve academic research consortium- 2 consensus document. J Am Coll Cardiol 60: 1438-1454.

12. Hoey, Mankad K, Al-Chalabi H, Rosa S (2013) The emerging role of cardiovascular MRI for suspected cardioembolic stroke. Clinical Radiology 68 : 107-116.

13. Khetarpal V, Mahajan N, Madhavan R, Batra S, Mopala P, et al. (2009) Calcific aortic valve and spontaneous embolic stroke: A review of literature. J Neurol Sci 287: 32-35.

14. Rodriguez CJ, Bartz TM, Longstreth WT, Kizer JR, Barasch E, et al. (2011) Association of annular calcification and aortic valve sclerosis with brain findings on magnetic resonance imaging in community dwelling older adults. $J$ Am Coll Cardiol 57: 2172-2180.

15. Sugioka K, Matsumura Y, Hozumi T, Fujita S, Ito A, et al. (2011) Relation of aortic arch complex plaques to risk of cerebral infarction in patients with aortic stenosis. Am J Cardiol 108: 1002-1007.

16. Goldberg I, Auriel E, Russell D, Korczyn AD (2012) Microembolism, silent brain infarcts and dementia. J Neurol Sci 322: 250-253.

17. Greve AM, Gerdts E, Boman K, Gohlke-Baerwolf C, Rossebø AB, et al. (2013) Prognostic importance of atrial fibrillation in asymptomatic aortic stenosis: The Simvastatin and Ezetimibe in Aortic Stenosis study. Int J Cardiol 166: $72-76$.

18. Dubois C, Coosemans M, Rega F, Poortmans G, Belmans A, et al. (2013) Prospective evaluation of clinical outcomes in all-comer high-risk patients with aortic valve stenosis undergoing medical treatment, transcatheter or surgical aortic valve implantation following heart team assessment. Interact Cardiovasc Thorac Surg 17: 492-500.

19. Saczkowski R, Malas T, de Kerchove L, El Khoury G, Boodhwani M (2013) Systematic review of aortic valve preservation and repair. Ann Cardiothorac Surg 2013: 3-9.

20. Boodhwani M, de Kerchove L, Glineur D, Rubay J, Vanoverschelde JL, et al. (2010) Repair of regurgitant bicuspid aortic valves: A systematic approach. J Thorac Cardiovasc Surg 140: 276-284.

21. Arinaga K, Fukunaga S, Tomoeda H, Hori H, Ueda T, et al. (2011) Twelveyear experience with the Carpentier- Edwards pericardial aortic valve at single Japanese center. J Artific Organs 14: 209-214
22. Wei X, Yi W, Chen W, Ma X, Lau LB, et al. (2010) Clinical outcomes with the Epicholorohydrin-Modified Porcine aortic heart valve: a 15-year follow-up. Ann Thor Surg 89:1417-1424.

23. Blair KL, Hatton AC, White WD, Smith LR, Lowe JE, et al. (1994) Comparison of anticoagulation regimens after Carpentier-Edwards aortic or mitral valve replacement. Circulation 90: II214-II219.

24. Heras M, Chesebro JH, Fuster V, Penny WJ, Grill DE, et al. (1995) High risk of thromboemboli early after bioprosthetic cardiac valve replacement. J Am Coll Cardiol 25: 1111-1119.

25. El Bardissi AW, Di Bardino DJ, Chen FY, Yamashita MH, Cohn LH (2010) Is early antithrombotic therapy necessary in patients with bioprosthetic aortic valves in normal sinus rhythm? J Thorac Cardiovasc Surg 139: 1137-1145.

26. Brennan JM, Edwards FH, Zhao Y, O'Brien S, Booth ME, et al. (2012) Early anticoagulation of bioprosthetic aortic valves in older patients results from the Society of Thoracic Surgeons Adult Cardiac Surgery National Database. J Am Coll Cardiol 60: 971-977.

27. Mérie C, Køber L, Olsen PS, Andersson C, Gislason G, et al. (2012) Association of warfarin therapy duration after bioprosthetic aortic valve replacement with risk of mortality, thromboembolic complications, and bleeding. JAMA 308: 2118-2125.

28. Durães AR, Durães MAO, Correia LC, Fernandes AMS, Aras R (2013) Impact of aspirin use in the incidence of thromboembolic events after bioprosthesis replacement in patients with rheumatic disease. Rev Bras Cir Cardiovasc 28: 347-352

29. Birla R, Twine G, Unsworth-White J (2013) Randomized trial of Carpentier-Edwards supra-annular prosthesis versus mosaic aortic prosthesis: 6 year results. Ann Thorac Surg 95: 831-837

30. Colli A, Verhoye JP, Heijmen R, Antunes M (2013) Low-dose acetyl salicylic acid versus oral anticoagulation after bioprosthetic aortic valve replacement Final report of the action registry. Int J Cardiol 168: 1229-1236.

31. Kodali SK, Williams MR, Smith CR, Svensson LG, Webb JG, et al. (2012) Two-year outcomes after transcatheter or surgical aortic-valve replacement. New Eng J Med 366: 1686-1695.

32. Miller DC, Blackstone EH, Mack MJ, Svensson LG, Kodali SK, et al. (2012) Transcatheter (TAVR) versus surgical (AVR) Aortic Valve Replacement: occurrence, hazard, risk factors, and consequences of neurologic events in the PARTNER trial. J Thorac Cardiovasc Surg 143: 832-843.

33. Tamburino C, Barbanti M, Capodanno D, Mignosa C, Gentile M, et al. (2012) Comparison of Complications and Outcomes to One Year of Transcatheter Aortic Valve Implantation Versus Surgical Aortic Valve Replacement in Patients With Severe Aortic Stenosis. Am J Cardiol 109: 1487-1493.

34. Knipp SC, Kahlert P, Jokisch D, Schlamann M, Wendt D, et al. (2013) Cognitive function after transapical aortic valve implantation: a single-centre study with 3-month follow-up. Interactive CardioVascular and Thoracic Surgery 16 116-122.

35. Panchal HB, Ladia V, Desai S, Shah T, Ramu V (2013) A Meta-Analysis of Mortality and Major Adverse Cardiovascular and Cerebrovascular Events Following Transcatheter Aortic Valve Implantation Versus Surgical Aortic Valve Replacement for Severe Aortic Stenosis. Am J Cardiol 112: 850-860.

36. Onorati F, Biancari F, De Feo M, Mariscalco G, Messina A, et al. (2013) Outcome of Redo Surgical Aortic Valve Replacement in Patients 80 Years and Older: Results From the Multicenter RECORD Initiative. Ann Thorac Surg 97: 537-543.

37. Li Y, Walicki D, Mathiesen C, Jenny D, Li Q, et al. (2009) Strokes After Cardiac Surgery and Relationship to Carotid Stenosis. Archiv Neurol 66: 1091 1096.

38. Knapik P, Ciesla D, Wawrzynczyk M, Knapik M, Borkowski J, et al. (2010) Incidence and prediction of permanent neurological deficits after cardiac surgery-are the existing models of prediction truly global? Eur $\mathrm{J}$ Cardio-thorac Surg 37: 717-723. 
39. Mahajan N, Khetarpal V, Afonso L (2009) Stroke secondary to calcific bicuspid aortic valve: Case report and literature review. J Cardiol 54: 158-161.

40. Natale, F, Aronne L, Credendino M, Siciliano A, Allocca F, et al. (2011) Which is the correct management of patients with asymptomatic severe calcific aortic stenosis after symptomatic spontaneous calcium cerebral embolism? J Cardiovasc Med 12: 428-429.

41. Chan KMJ, Rahman-Haley S, Mittal TK, Gavino JA, Dreyfus GD (2011) Truly stentless autologous pericardial aortic valve replacement: An alternative to standard aortic valve replacement. J Thorac Cardiovasc Surg141: 276-283.

42. Whitlock RP, Eikelboom JW (2012) Prevention of Thromboembolic Events After Bioprosthetic Aortic Valve Replacement What Is the Optimal Antithrombotic Strategy? J Am Coll Cardiol 60: 978-980

43. Mydin MI, Dimitrakakis G, Younis J, Nowell J, Athanasiou T, et al. (2012) Optimal thromboprophylaxis following bioprosthetic aortic valve replacement: still a matter of debate? Interactive Cardiovascular and Thoracic Surgery 15 109-114.

44. Al-Atassi T, Lam K, Forgie M, Boodhwani M, Rubens F, et al. (2012) Cerebra microembolization after bioprosthetic aortic valve replacement: Comparison of warfarin plus aspirin versus aspirin only. Circulation 126: S239-S244.

45. Kaatz S, Gage BF (2013) Top practice-changing articles over the last two years. J Thrombosis Thrombolysis 35: 325-332.

46. Rodés-Cabau J, Dauerman HL, Cohen MG, Mehran R, Small EM, et al. (2013) Antithrombotic Treatment in Transcatheter Aortic Valve Implantation Insights for Cerebrovascular and Bleeding Events. J Am Coll Cardiol 62 2349-2359.

47. Smith CR, Leon MB, Mack MJ, Miller C, Moses JW, et al. (2011) Partner Tria Investigators. Transcatheter versus surgical aortic-valve replacement in highrisk patients. New Eng J Med 364: 2187-2198.

48. Doss M, Buhr EB, Martens S, Moritz A, Ziere A (2012) Transcatheter-based aortic valve implantations at mid-term: what happened to our initial patients? Ann Thorac Surg 94: 1400-1406.

49. Webb JG, Wood DA (2012) Current status of transcatheter aortic valve replacement. J Am Coll Cardiol 60: 483-492.

50. Tay EL, Gurvitch R, Wijesinghe N, Nietlispach F, Wood D, et al. (2011) A high-risk period for cerebrovascular events exists after transcatheter aortic valve implantation. JACC-Cardiovascular Interventions 4:1290-1297.
51. Stortecky S, Buellesfeld L, Wenaweser P, Heg D, Pilgrim T, et al. (2013) Atrial fibrillation and aortic stenosis: impact on clinical outcomes among patients undergoing transcatheter aortic valve implantation. Circ-Cardiovasc Int 6: $77-84$.

52. Ussia GP, Scarabelli M, Mulè M, Barbanti M, Sarkar K, et al. (2011) Dual antiplatelet therapy versus aspirin alone in patients undergoing transcatheter aortic valve implantation. Am J Cardiol 108: 1772-1776.

53. Ghanem A, Kocurek J, Sinning JM, Wagner M, Becker B, et al. (2013) Cognitive trajectory after transcatheter aortic valve implantation. Circ Cardiovasc Int 6: 615-624.

54. Ghanem A, Muller A, Sinning JM, Kocurek J, Becker BV, et al. (2013) Prognostic value of cerebral injury following transfemoral aortic valve implantation. Euro Intervention 8: 1296-1306.

55. Kahlert P, Knipp SC, Schlamann M, Thielmann M, Al-Rashid F, et al. (2010) Silent and apparent cerebral ischemia after percutaneous transfemoral aortic valve implantation a diffusion-weighted magnetic resonance imaging study. Circulation 121: 870-878.

56. Hauville C, Ben-Dor I, Lindsay J, Pichard AD, Waksman R (2012) Clinical and silent stroke following aortic valve surgery and transcatheter aortic valve implantation. Cardiovascular Revascularization Medicine 13: 133-140.

57. Horstkotte D, Lengyel M, Mistiaen WP, Piper C, Völler H, et al. (2005) Recommendations for Reporting Morbid Events after Heart Valve Surgery. $J$ Heart Valve Dis 14: 1-7

58. Horstkotte D, Lengyel M, Mistiaen WP, Völler H, Reibis R, et al. (2007) Recommendations for Post-Discharge Patient Follow Up after Cardiac Valve Interventions: A Position Paper. J Heart Valve Dis 16: 575-589.

59. Beholz S, Repossini A, Livi U, Schepens M, El Gabry M, et al. (2010) The Freedom SOLO Valve for Aortic Valve Replacement: Clinical and Hemodynamic Results from a Prospective Multicenter Trial. J Heart Valve Dis 19: 115-123.

60. Jamieson WR, Fradet GJ, Abel JG, Janusz MT, Lichtenstein SV, et al. (2009) Seven-year results with the St Jude Medical Silzone mechanical prosthesis. J Thorac Cardiovasc Surg 137: 1109-1115. 